\title{
DOAÇÃO: ASPECTOS GERAIS E DOAÇÃO ENTRE ASCENDENTE E DESCENDENTE
}

\author{
DONATION: GENERAL ASPECTS AND DONATION BETWEEN ASCENDANTS AND DESCENDANTS
}

\section{Daniela Braga Paiano*}

\begin{abstract}
Resumo:
O presente trabalho tem por objetivo analisar a relevância do tema doação e em especial alguns assuntos polêmicos concernentes à temática. Para tanto, inicia-se veiculando alguns fatos trazidos pela mídia bem como alguns julgados exemplificativos que elucidam seu estudo. Uma vez que o tema se relaciona com diversos campos do Direito Civil, percebe-se a preocupação do legislador ao tratálo, tentando evitar a ocorrência de eventuais lesões a direito. Desta feita, na primeira parte deste artigo, serão abordados alguns aspectos gerais com relação à doação, tais como as espécies, classificação, sua natureza jurídica, restrições à liberdade de testar, elucidando-se com casos em concreto. Após, analisar-se-á o tema doação como forma de adiantamento da legítima e a questão da nulidade da doação que exceder a parte disponível prevista no art. 549 do Código Civil. Finalmente, será tratada a questão da necessidade de colação ou não dos bens recebidos para se falar da redução das disposições recebidas no caso de doações inoficiosas.
\end{abstract}

Palavras-chave: Doação. Adiantamento da legítima. Doação inoficiosa.

\begin{abstract}
:
This study aims to analyze the relevance of donation, especially some controversial issues concerning this subject. For this purpose, some facts brought by the media as well as some examples from judged cases to elucidate it were presented. Once the subject is related to all aspects of civil law, one realizes the concern of the legislature to address the issue, trying to avoid and prevent any injuries to rights. So, in the first part of this article, it will be analyzed some general aspects concerning relation to the donation, such as types, classification, legal status, restrictions on freedom to test and the elucidation of cases by courts in judgments. After that, donation will be analyzed as a way to advance in inheritance and the issue of nullity of the donation when it exceeds the amount available provided by the article 549 of Brazilian Civil Code. Finally, it will discuss the need to collation or not the goods received in case of nonofficial donations.
\end{abstract}

Keywords: Donation. Advance in inheritance. Unofficial donations.

\footnotetext{
Mestre em Direito, doutoranda do curso de pós-graduação em Direito da Faculdade de Direito da Universidade de São Paulo. Advogada. Professora da Universidade Estadual de Londrina - UEL. E-mail: danielapaiano@hotmail.com e danielapaiano@usp.br.
} 
Introdução

Em pesquisa realizada pelo IDIS (Instituto para o Desenvolvimento do Investimento Social) e a Ipsos Public Affairs, veiculado no jornal Folha de S.Paulo, constatou-se que a forma mais comum de doação é a feita para mendigos, principalmente em semáforos, ao lado de doação para igrejas. Isso revela que a doação feita no Brasil é de cunho assistencialista (30\% de predileção) e não feita de forma organizada para ONGS (14\% de predileção). O estudo informa que o impacto seria mais positivo se fosse feito para organizações sociais. ${ }^{1}$ Ressalta Agostinho Alvim que a economia pública também lucra com as doações tendo em vista que elas ativam a circulação da riqueza. ${ }^{2}$

Em outro recém-publicado artigo veiculado também pela Folha de S.Paulo, o Prof. Carlos Bastide Horbach aborda o tema "Doação com encargo e revogação" e lembra a questão de doações importantes em prol da sociedade, a exemplo dos museus que são localizados em imóveis doados, ressaltando que tais doações são acompanhadas por imposições aos donatários ou legatários, sob pena de serem revogadas. ${ }^{3}$

Neste artigo o Professor questiona a possibilidade de revogação da doação de um terreno em 1940 à União com o encargo da construção de um aeródromo militar. Tal encargo foi descumprido uma vez que a gestão da área não está vinculada a autoridade militar (2011) e porque em 2012 foi dada em concessão para exploração do aeroporto à iniciativa privada. $\mathrm{O}$ problema se torna ainda maior uma vez que a referida área abriga o Aeroporto Internacional de Guarulhos. ${ }^{4}$

Essas polêmicas envolvendo o tema doação ocorrem porque, conforme preleciona a doutrina, tal liberalidade "implica aumento do patrimônio do donatário e corresponde diminuição do patrimônio do doador". ${ }^{5}$ Ou seja, existe um cuidado da sociedade para que tais relações jurídicas não acarretem lesão ao direito de ninguém.

O estudo das doações é algo que envolve tanto a parte geral no que tange à validade e eficácia dos negócios jurídicos, bem como os defeitos dos mesmos, prazos decadenciais e prescricionais na teoria geral, passando pelo campo dos contratos

\footnotetext{
1 A tendência para doar esmolas é maior na região Nordeste (40\%) e entre os mais pobres (33\%). Nas classes A e B, a solidariedade com ONGs foi citada com maior frequência (17\%), mas ainda atrás das igrejas (25\%), que empatam tecnicamente com os pedintes $(27 \%)$. Entre as razões para não doar, foram citadas falta de dinheiro (54\%), falta de pedido de auxílio (18\%) e desconfiança nas ONGs (12\%). Disponível em: $<$ http://www1.folha.uol.com.br/cotidiano/2014/03/1422836-brasileiro-doa-mais-para-mendigos-e-igrejasdiz-estudo.shtml>. Acesso em: 11 mar. 2014.

$2 \quad$ ALVIM, Agostinho Neves de Arruda. Da doação. 2. ed. atual. São Paulo: Saraiva, 1972. p. 5.

3 HORBACH, Carlos Bastide. Doação com encargo e revogação. Folha de S.Paulo, São Paulo, 4 abr. 2014. Opinião, Caderno, p. A3. Disponível em: <http://www1.folha.uol.com.br/opiniao/2014/04/1435530-carlosbastide-horbach-doacao-com-encargo-e-revogacao.shtml>. Acesso em: 4 abr. 2014.

$4 \quad$ Id. Ibid.

5 LÔBO, Paulo. Direito civil: contratos. São Paulo: Saraiva, 2011. p. 285.
} 
propriamente ditos, pois é onde está situada tal figura jurídica, pelo instituto do usufruto nos direitos reais, pelo regime de bens em direito de família e ainda a questão sucessória com relação às doações inoficiosas e redução das disposições testamentárias ou ainda como adiantamento da legítima. Percebe-se que doação é um tema que permeia o Direito Civil como um todo. Por isso a relevância do tema e o cuidado que se deve ter em seu estudo.

1. Da doação - aspectos gerais

Cumpre destacar, de início, que o homem é dotado de direitos e deveres considerado na relação ao seu próximo. No que tange aos bens jurídicos exteriores ao ser humano, ou seja, aqueles que não envolvem os direitos da personalidade, estes recebem a atuação do direito e são sempre de cunho econômico, denominando-se direitos patrimoniais. Esses direitos dividem-se em direitos reais e os obrigacionais. ${ }^{6}$ Dos direitos obrigacionais, decorrem as relações jurídicas contratuais.

No que tange aos contratos em geral, afirma Marcos de Almeida Villaça Azevedo que o contrato é necessário para o desenvolvimento das atividades pessoais e profissionais, como um instrumento que harmonize interesses econômicos com os de outras pessoas. Por meio dos contratos, afirma o doutrinador que as partes adquirem bens e serviços, atingindo suas metas e seus objetivos. ${ }^{7}$

Aliás, a sociedade vivencia uma fase de modernização e de inseguranças. Nessa modernidade tardia, a produção social de riquezas é acompanhada sistematicamente pela produção social dos riscos, conforme menciona Ulrich Beck. ${ }^{8}$

Neste sentido, afirma Cláudia Lima Marques que a fase atual da pósmodernidade necessita de uma resposta de valorização do paradigma da confiança, tendo em vista que estes tempos parecem fadados ao aumento dos litígios e da desconfiança entre os agentes econômicos, com reflexos no direito privado. ${ }^{9}$

A grande importância do contrato é que a lei reconhece aos particulares um amplo poder de fornecer, com o próprio ato de vontade, esse acordo patrimonial, regulando essas relações. ${ }^{10}$

6 AZEVEDO, Álvaro Villaça. Teoria geral das obrigações e responsabilidade civil. 12. ed. São Paulo: Atlas, 2011. p. 1-2.

7 AZEVEDO, Marcos de Almeida Villaça. Onerosidade excessiva e desequilibrio contratual supervenientes. 2002. Tese (Doutorado) - Faculdade de Direito, Universidade de São Paulo, São Paulo, 2002. p. 3.

8 BECK, Ulrich. Sociedade de risco: rumo a uma outra modernidade. Tradução de Sebastião Nascimento. São Paulo: Ed. 34, 2010. p. 23.

9 MARQUES, Cláudia Lima. A chamada nova crise do contrato e o modelo de direito privado brasileiro: crise de confiança ou crescimento do contrato? In: MARQUES, Cláudia Lima. (Org.). A nova crise do contrato: estudos sobre a nova teoria contratual. São Paulo: Revista dos Tribunais, 2007. p. 17-86. p. 21.

10 GALGANO, Francesco. Diritto privato. 15. ed., con 7 tavole di diritto comparato. Padova: CEDAM, 2010. p. 223. 
O negócio jurídico, segundo o Professor Álvaro Villaça Azevedo é “a manifestação de vontade tendente à criação, modificação ou extinção de uma relação jurídica". ${ }^{11}$ A doutrina afirma que "o contrato é a espécie mais importante dos negócios jurídicos". ${ }^{12}$

Desta forma, contrato pode ser conceituado como a "manifestação de duas ou mais vontades, objetivando criar, regulamentar, alterar ou extinguir uma relação jurídica (direitos e obrigações) de caráter patrimonial". ${ }^{13}$ Afirma o professor que os contratos podem ser divididos em contratos em típicos e atípicos:

Os contratos típicos recebem do ordenamento jurídico uma regulamentação particular, e apresentam-se com um nome, ao passo que os atípicos, embora possam ter um nome, carecem de disciplina particular, não podendo a regulamentação dos interesses dos contratantes contrariar a lei, a ordem pública, os costumes e os princípios gerais do direito. ${ }^{14}$

Lembra Alberto Trabucchi que os contratos podem ter classificações por diversos critérios, podendo ser solenes ou não, onerosos ou gratuitos, nominados e inominados, principais e acessórios, normativos, coletivos e adesivos e outras mais. ${ }^{15}$

Dentre os contratos em espécies tipificados no Código Civil brasileiro, encontra-se a doação, disposta entre os arts. 538 a 564. Aliás, a natureza jurídica da doação no ordenamento civil brasileiro é de ordem contratual. ${ }^{16}$ Afirma Orlando Gomes que foi abandonada pela doutrina a concepção de que doação seria modo de adquirir propriedade, proveniente das Institutas e passou a ser considerado pelo Direito moderno como contrato, sendo negócio jurídico de natureza especial. ${ }^{17}$ Considerando que o contrato de doação é apenas o título, a causa da transferência, afirma Orlando Gomes que tal contrato é de natureza obrigacional e não real. Cumpre lembrar que a propriedade é transferida, quando móvel o bem, pela tradição, e se imóvel, pelo registro. ${ }^{18}$ No Direito Romano a doação não tinha um caráter de constituir negócio jurídico típico, mas apenas era uma causa justificante de se realizar uma atribuição patrimonial sem um correspectivo. ${ }^{19}$

11 AZEVEDO, Álvaro Villaça. Teoria geral dos contratos típicos e atípicos. 3. ed. São Paulo: Atlas, 2009. p. 8.

12 JORGE JÚNIOR, Alberto Gosson. Direito dos contratos. São Paulo: Saraiva, 2013. p. 23.

13 AZEVEDO, Álvaro Villaça. Teoria geral dos contratos típicos e atípicos .... cit., p. 9.

14 AZEVEDO, Álvaro Villaça. Comentários ao novo código civil: das várias espécies de contrato, da compra e venda e do compromisso de compra e venda. Arts. 481 a 532. Coord. Sálvio de Figueiredo Teixeira 2. ed. Rio de Janeiro: Forense, 2011. v. 7. p. 21 e 22.

15 TRABUCCHI, Alberto. Istituzioni di diritto civile. 44. ed. Padova: CEDAM, 2009. p. 202.

16 LÔBO, Paulo. Direito civil ... op. cit., p. 283.

17 GOMES, Orlando. Contratos. 9. ed. Rio de Janeiro: Forense, 1983. p. 233.

18 Id. Ibid., p. 235.

19 CASULLI, Vincenzo Rodolfo. Donazioni indirette e rinunzie ad eredita o legati. Roma: Foro Italiano, 1950. p. 9. 
Diferentemente, o Código Civil francês estuda a doação dentre os modos de aquisição da propriedade, na parte de liberalidades, de quem pode receber e fazer a doação por ato entre vivos, disciplinando o instituto dos arts. 901 e seguintes, iniciando o estudo com a capacidade para essa liberalidade. ${ }^{20}$ Segundo Eduardo Espínola, o Código Civil francês estuda a doação como ato e não como contrato, considerando-a como forma de aquisição de propriedade. Assevera que no mesmo sentido estão os códigos espanhol, chileno, colombiano e boliviano. ${ }^{21}$

Conceitua o Prof. José Fernando Simão que o vocábulo doação tem duas acepções no direito: “doação em sentido amplo e o negócio jurídico denominado doação. Em sentido amplo, é doação a atribuição patrimonial. Assim, qualquer vantagem patrimonial que se atribui a alguém sem contrapartida, é doação em sentido amplo." ${ }^{22}$

Pontes de Miranda ao explicar a etimologia de doação, afirma que essa recebe dois sentidos: "um largo, que abrange qualquer liberalidade; outro estreito, que só se refere à liberalidade com a coisa." ${ }^{23}$

Define como doação o "negócio jurídico bilateral, ou seja, nasce de um acordo de vontades, logo, no plano da existência do negócio jurídico, não há contrato se não houver aceitação da outra parte. É nesse amálgama de vontades que nasce o contrato chamado doação". ${ }^{24}$ No mesmo sentido entende Pontes de Miranda ser a natureza jurídica da doação um negócio jurídico bilateral gratuito (e causal - porque a causa está na liberalidade). ${ }^{25}$ Vai além, menciona o referido doutrinador que é negócio jurídico bilateral, mas contrato unilateral (a doação pressupõe bilateralidade do negócio, sem bilateralidade do contrato). ${ }^{26}$ A mesma opinião compartilha Eduardo Espínola no sentido de ser um contrato unilateral, mas constituído pelo acordo de duas vontades, a do doador, que promete e a do donatário que aceita. ${ }^{27}$ Já para Paulo Lôbo, a doação é negócio jurídico unilateral, porque tanto a oferta quanto a aceitação vinculam a partir da manifestação de

20 Code Civil Français. Disponível em: <http://www.legifrance.gouv.fr/affichCode.do;jsessionid=9FEDF9B 6C51FA1CA5AFEB8DE089F884E.tpdjo01v_2?idSectionTA=LEGISCTA000006150544\&cidTexte=LEG ITEXT000006070721\&dateTexte $=20140406>$. Acesso em: 6 abr. 2014.

21 ESPÍNOLA, Eduardo. Dos contratos nominados no direito civil brasileiro. Atualizado por Ricardo Rodrigues Gama. Campinas: Bookseller, 2002. p. 226.

22 SIMÃO, José Fernando. Natureza jurídica do dízimo e da doação: aparente semelhança, mas grandes e insuperáveis diferenças. Disponível em: $<$ http://www.professorsimao.com.br/artigos_simao_cf0813.html >. Acesso em: 16 mar. 2014.

23 MIRANDA, Francisco Cavalcanti Pontes de. Tratado de direito privado. Parte especial. 2. ed. Rio de Janeiro: Editor Borsoi, 1964. t. 46. p. 191.

24 SIMÃO, José Fernando. Natureza jurídica do dízimo e da doação: aparente semelhança, mas grandes e insuperáveis diferenças. Disponível em: <http://www.professorsimao.com.br/artigos_simao_cf0813.htmll. Acesso em: 16 mar. 2014.

25 MIRANDA, Francisco Cavalcanti Pontes de. Tratado de direito privado ... cit., p. 197.

26 Id. Ibid., p. 198.

${ }_{27}$ ESPÍNOLA, Eduardo. Dos contratos nominados ... cit., p. 225. 
vontade do ofertante o aceitante, independente da manifestação do outro. ${ }^{28}$ No mesmo sentido entende Paulo de Tarso V. Sanseverino, de ser unilateral porque a doação estabelece deveres apenas para o doador. ${ }^{29}$

Assevera Agostinho Alvim que "A doação é contrato unilateral, pois só uma das partes contrai obrigação, a saber, o doador, que se obriga a entregar a coisa. $\mathrm{O}$ donatário não assume nenhuma obrigação". ${ }^{30}$ Fabrício Zamprogna Matiello afirma que a doação é um contrato unilateral porque apenas o doador fica obrigado a entregar o bem objeto do negócio jurídico. O fato de haver doações com encargo não tornam a doação bilateral porque o núcleo obrigacional sempre reside no polo do doador. ${ }^{31}$

Orlando Gomes conceitua doação como o "contrato pelo qual uma das partes se obriga a transferir gratuitamente um bem de sua propriedade para o patrimônio de outra, que se enriquece na medida em que aquela empobrece". 32

Esclarece Pontes de Miranda que "com o aumento do patrimônio do donatário diminui-se o do doador. Se não há causalidade entre essa diminuição e aquele aumento, não há doação". ${ }^{33}$ Aliás, complementa mencionando que "o propósito de enriquecer não é essencial. O que é essencial é a intenção de doar". ${ }^{34}$

Afirma Paulo de Tarso Vieira Sanseverino que "o elemento subjetivo da doação é o animus donandi, que corresponde ao espírito de liberalidade que deve estar necessariamente presente no contrato". ${ }^{35}$ Neste sentido Alfredo Ascoli menciona que são características da doação a gratuidade e o animus donandi. ${ }^{36}$

A doutrina italiana entende que a causa é a função econômico-social do ato de vontade; a justificação da autonomia privada. ${ }^{37}$

O Código Civil brasileiro, em seu art. 538, conceitua doação como o ato de liberalidade em que uma pessoa transfere do seu patrimônio, bens ou vantagens para outra. ${ }^{38}$ Também o Código Civil italiano em seu art. 769, define doação como contrato (782, 1.321 e seguintes), com espírito de liberalidade, uma parte enriquece o outro,

\footnotetext{
$28 \quad$ LÔBO, Paulo. Direito civil ... cit., p. 286.

29 SANSEVERINO, Paulo de Tarso Vieira. Contratos nominados II: contrato estimatório, doação, locação de coisas, empréstimo (comodato-mútuo). São Paulo: Revista dos Tribunais, 2005. p. 69.

30 ALVIM, Agostinho Neves de Arruda. Da doação ... cit., p. 7.

31 MATIELlO, Fabrício Zamprogna. Código civil comentado: Lei n. 10.406, de 10.1.2001. 5. ed. São Paulo: LTr, 2013. p. 352.

32 GOMES, Orlando. Contratos ... cit., p. 233.

33 MIRANDA, Francisco Cavalcanti Pontes de. Tratado de direito privado ... cit., p. 194.

34 Id. Ibid., p. 198.

35 SANSEVERINO, Paulo de Tarso Vieira. Contratos nominados II ... cit., p. 64.

36 ASCOLI, Alfredo. Trattato delle donazioni. 2. ed. riv. Milano: Società Editrice Libraria, 1935. p. 72.

37 GAGLIANO, Pablo Stolze. O contrato de doação ... cit., p. 242.

38 BRASIL. Código Civil. Disponível em: <http://www.planalto.gov.br/ccivil_03/leis/2002/L10406.htm>. Acesso em: 5 abr. 2014.
} 
dispondo a seu favor um direito ou assumindo uma obrigação para com este. ${ }^{39}$ Não foi de modo diferente que o Código Civil português tratou o tema em seu art. $940 .{ }^{40}$ Já o Código Civil espanhol, em seu art. 618, classifica a doação como ato e não como contrato, seguindo a linha do código francês: "um ato de liberalidade pelo qual uma pessoa dispõe gratuitamente de uma coisa em favor de outra, que a aceita". ${ }^{41}$ Destaca a doutrina espanhola ao explicar tal artigo, que o donatário pode aceitá-la gratuitamente ou tendo que fazer uma contraprestação. ${ }^{42}$

Com relação a tal disposição legal, explica a doutrina espanhola que apenas bens presentes podem ser doados, podendo, inclusive, doar todo seu patrimônio, reservando para si a propriedade plena ou parte dela em usufruto, afirma que não pode o doador, pelo ato da doação, diminuir substancialmente seu nível de vida. ${ }^{43}$ Tal disposição se encontra expressa no art. 634 do Código Civil de tal país.

No Brasil, com relação à doação total do patrimônio, existe um cuidado do Estado para que a pessoa não fique sem patrimônio algum, declarando no art. 548 do CC ser nula tal doação. Desta feita, a doação universal seria um tipo de doação proibida, ao lado da doação inoficiosa. ${ }^{44}$

No que concerne a esse cuidado feito pelo Estado, destaca o Prof. Eduardo Tomasevicius Filho que "Por meio da atuação legislativa como também da atividade judicial, o Estado foi atenuando a força obrigatória dos contratos, quando, por exemplo, o seu cumprimento levasse o devedor à ruína $(. .). "{ }^{45}$

Afirma Sanseverino que "as restrições à liberdade de doar buscam proteger o próprio doador e determinadas pessoas a ele relacionadas (cônjuge, herdeiros necessários ou credores)". 46

O legislador pátrio cuidou das restrições à liberdade de testar quando declara como nula a doação universal, abrangendo todos os bens, em seu art. 548, conforme já mencionado acima e quando trata da doação inoficiosa, em seu art. 549, qual seja, aquela que excede a parte disponível caso existam herdeiros necessários, invadindo-se a legítima.

39 Codice Civile Italiano. Disponível em: <http://www.jus.unitn.it/cardozo/obiter_dictum/codciv/Lib2.htm>. Acesso em: 6 abr. 2014.

40 Código Civil Português. Disponível em: <http://www.igf.min-financas.pt/leggeraldocs/DL_47344_66_ COD_CIVIL_4.htm\#CODIGO_CIVIL_ARTIGO_940>. Acesso em: 6 abr. 2014.

${ }_{41}$ Código Civil espanhol. Disponível em: $<$ http://civil.udg.es/normacivil/estatal/CC/3T2.htm>. Acesso em: 5 abr. 2014.

42 GALES NAVARRO, Santiago. Todo lo que usted necesita saber sobre herencias, testamentos y donaciones. Barcelona: Inforbook's, 1998. p. 165.

43 Id. Ibid., p. 169-170.

44 LÔBO, Paulo. Direito civil ... cit., p. 303.

45 TOMASEVICIUS FILHO, Eduardo. Uma década da aplicação da função social do contrato: análise da doutrina e da jurisprudência brasileiras. Revista dos Tribunais, v. 103, n. 940, p. 49-85, fev. 2014. p. 52.

46 SANSEVERINO, Paulo de Tarso Vieira. Contratos nominados II ... op. cit., p. 82. 
Essa restrição também existe quando se prejudica credores (art. 158 do Código Civil) e quando feita por cônjuge adúltero ao seu cúmplice (art. 550, CC). ${ }^{47}$

Quanto aos efeitos desses atos, esclarece o Professor Álvaro Villaça Azevedo no que tange ao ato nulo que este "não é passível de convalescimento, de ratificação, sendo, desse modo, incorrigível, insanável sua imperfeição. Por sua vez, o ato anulável quando sua imperfeição for corrigível, sanável, convalescendo, portanto, sendo suscetível de ratificação". ${ }^{48}$

Destaca o professor que "a venda de ascendente para descendente somente pode ser considerada anulável, nunca nula, não só por poder ela encobrir uma simulada doação mas, também, e principalmente, por poder sanar-se sua imperfeição pela posterior aquiescência dos demais descendentes". ${ }^{49}$

Assim, entende o Professor Álvaro Villaça Azevedo que para o caso de compra e venda entre ascendente e descendente seria necessário a aquiescência dos demais, sob pena de ser considerada anulável, nunca inexistente ou nula. Reitera novamente aqui que tal fato pode encobrir uma doação simulada..$^{50}$

Em julgado do TJ/SC ocorreu uma doação simulada dos pais para apenas um dos seis filhos, uma vez que estes doaram ao filho menor de idade e fizeram constar como se fosse um pagamento por serviços prestados, sendo que este bem era o único imóvel do casal no momento da liberalidade. O casal, quando se divorciou, não fez constar a existência de nenhum bem imóvel. Os demais filhos foram preteridos uma vez que tal ato se tratou de uma doação indireta, inoficiosa, que comporta a anulação pela invasão da legítima. Foi o que ocorreu no caso..$^{51}$

Aliás, a leitura das doações deve ser feita com outros institutos do direito, em especial o da boa-fé. Neste sentido assevera o Prof. José Fernando Simão que o estudo da boa-fé é essencial para os contratos e obrigações. ${ }^{52}$

47 SANSEVERINO, Paulo de Tarso Vieira. Contratos nominados II ... op. cit., p. 82-84.

48 AZEVEDO, Álvaro Villaça. Venda de ascendente a descendente. Revista dos Tribunais, ano 71, v. 565, p. 39-48, nov. 1982. p. 43.

49 Id. Ibid., loc. cit.

50 AZEVEDO, Álvaro Villaça. Considerações sobre a venda de ascendente para descendente, ante as súmulas 152 e 494 do STF. Revista de Direito Civil Imobiliário, Agrário e Empresarial, São Paulo, ano 4, n. 13, p. 161-173, jul./set. 1980. p. 167. Ante as súmulas 152 e 494 do STF.

51 Ação de nulidade de ato jurídico. Compra e venda de imóvel. Simulação. Doação inoficiosa Tribunal TJSC. Data: 20/03/2014. Apelação Cível n. 2009.037359-1, de Timbó. Disponível em: <http://ibdfam.org.br/ jurisprudencia/2352/A\%C3\%A7\%C3\%A3o\%20de\%20nulidade $\% 20 \mathrm{de} \% 20$ ato $\% 20 \mathrm{jur} \% \mathrm{C} 3 \% \mathrm{ADdico} \% 20$ Compra\%20e\%20venda\%20de $\% 20$ im $\%$ C3\%B3vel.\%20Simula $\%$ C3\%A7\%C3\%A3o.\%20Doa\%C3\%A7\%C3\%A3o\%20inoficiosa>. Acesso em: 20 mar. 2014.

52 SIMÃO, José Fernando. A boa-fé objetiva: nova disciplina de um velho instituto. Revista da Faculdade de Direito, Fundação Álvares Penteado, São Paulo, ano 3, v. 3, p. 162-178, 2005-2006. p. 163. 
A doação é por vezes utilizada quando o doador já se encontra em insolvência e doa um imóvel aos filhos. Tal doação é considerada como fraude contra credores. ${ }^{53}$

Um caso curioso julgado pelo STJ foi o de uma pessoa tentando revogar a ‘doação’ de dízimo feita à igreja. No caso em comento o STJ mencionou que não se trata de uma doação, pois se trata de ato de voluntariedade, como um dever de consciência religiosa, não se definindo como contrato típico de doação. Esclareceu, ainda, que doações feitas para igrejas são para a pessoa jurídica e por isso não podem ser revogadas por ingratidão. ${ }^{54}$

As irregularidades relacionadas a doações ocorrem não apenas no âmbito das relações privadas, mas também como atos de improbidade administrativa. É o caso de doação de verba pública sem lei que autorizasse tal repasse ao Londrina Esporte Clube decidido pelo STJ. ${ }^{55}$

Com relação à classificação das doações, o Prof. Carlos Alberto Bittar afirma que se trata de um contrato unilateral, consensual e gratuito.

Unilateral porque somente o doador assume a obrigação; consensual, pois se aperfeiçoa com a simples convergência de vontades, nascendo da aceitação do donatário o dever de entregar; e gratuito, uma vez que ao acréscimo patrimonial do contemplado não corresponde o ingresso de vantagem alguma para o doador. Aliás, mesmo na doação com encargo inexiste o sinalagma, reafirmando-se, pois, os caracteres expressos. $^{56}$

Afirma Orlando Gomes que é unilateral porque somente o doador contrai obrigações. Simplesmente consensual porque não requer para seu aperfeiçoamento a entrega da coisa dada ao donatário. Gratuito por excelência. ${ }^{57}$

53 AGRAVO REGIMENTAL NO AGRAVO EM RECURSO ESPECIAL. FRAUDE CONTRA CREDORES. EMBARGOS DE TERCEIRO. DOAÇÃO A FILHOS. INEFICÁCIA PERANTE A EXECUÇÃO. REEXAME DE FATOS E PROVAS. SÚMULA N. 7/STJ. DECISÃO AGRAVADA MANTIDA. IMPROVIMENTO. 1.- A doação de bem imóvel da executada insolvente aos filhos, caracteriza má-fé por fraude contra credores, nos termos da Súmula n. 375 do Superior Tribunal de Justiça. As razões do Recurso Especial, na parte relativa à prova da má-fé, não vem amparadas em alegação de ofensa a lei federal nem em dissídio pretoriano, merecendo aplicação a Súmula n. 284/STF. Nessa medida restaria hígido o fundamento do Acórdão relativo à comprovação de má-fé, o que seria suficiente para manutenção do julgado. (...) AgRg. no AREsp. 413.948/RS, Rel. Ministro Sidnei Beneti, Terceira Turma, julgado em 26/11/2013, DJe 3/12/2013). Disponível em: <http://www.stj.jus.br>. Acesso em: 1 mar. 2014.

54 (REsp. 1371842/SP, Rel. Ministro Sidnei Beneti, Terceira Turma, julgado em 19/11/2013, DJe 17/12/2013). Disponível em: <http://www.stj.jus.br>. Acesso em: 1 mar. 2014.

55 (REsp. 987.598/PR, Rel. Ministro Napoleão Nunes Maia Filho, Primeira Turma, julgado em 27/08/2013, DJe 19/09/2013). Disponível em: <http://www.stj.jus.br>. Acesso em: 1 mar. 2014.

${ }_{56}$ BITTAR, Carlos Alberto. Contratos civis. 3. ed. Rio de Janeiro: Forense Universitária, 2006. p. 42-43.

57 GOMES, Orlando. Contratos ... cit., p. 233. 
Acrescenta o Prof. José Fernando Simão que eles seriam típicos e solenes (devendo ser realizados por escritura pública ou documento particular, ainda pelo modo verbal quando se tratar de bens móveis). ${ }^{58}$ É o que preceitua o art. 541 do CC.

Já no Código Civil francês, em seu art. 931, menciona-se que todos os atos de entre vivos serão feitos na forma de um contrato e deverão passar por um notário, sob pena de nulidade. ${ }^{59}$

Interessante destacar um caso em que o STJ analisou, da 'confusão' realizada pelos pais. Um casal fez doação de um imóvel para seus filhos, porém, não efetuou o registro da doação. Após, fizeram um contrato de mútuo bancário, dando tal bem em garantia para o banco! Afirmou-se no julgado a legitimidade dos filhos ingressarem com embargos de terceiro, já que o imóvel lhes pertencia. ${ }^{60}$

No que tange às espécies, a doutrina afirma serem: pura e simples (verdadeiro espírito de generalidade, não subordinando a nenhuma condição), modal ou onerosa (doador estabelece um encargo ao donatário), remuneratória (agradecer um serviço prestado). ${ }^{61}$ Afirma Pontes de Miranda que na doação remuneratória remunera-se sem dever; para ele, essa doação só é remuneratória no motivo, daí sua unilateralidade. ${ }^{62}$ Para ele, também, na doação modal, o donatário é vinculado ao modus. ${ }^{63}$ Aliás, com relação a essa espécie de doação, afirma que se houver vício de direito ou de objeto e se o que se doou não bastar para cumprir o modus, pode o donatário recusar-se a cumprir o que prometeu até que se compense o importe da diferença. ${ }^{64}$

$58 \quad$ SIMÃO, José Fernando. Direito civil: contratos. 2. ed. São Paulo: Atlas, 2007. v. 5. p. 127.

59 Code Civil Français. Disponível em: <http://www.legifrance.gouv.fr/affichCode.do;jsessionid=9FEDF9B 6C51FA1CA5AFEB8DE089F884E.tpdjo01v_2?idSectionTA=LEGISCTA000006150544\&cidTexte=LEG ITEXT000006070721\&dateTexte=20140406>. Acesso em: 6 abr. 2014.

60 AGRAVO REGIMENTAL NOS EMBARGOS DE DECLARAÇÃO NO RECURSO ESPECIAL. EMBARGOS DE TERCEIRO. PENHORA DE IMÓVEL. ANTERIOR DOAÇÃO FEITA PELOS GENITORES AOS FILHOS MENORES EM AÇÃO DE SEPARAÇÃO JUDICIAL, DEVIDAMENTE HOMOLOGADA. FALTA DE REGISTRO NO CARTÓRIO DE IMÓVEIS. POSTERIOR CONTRATO DE MÚTUO CELEBRADO ENTRE OS GENITORES E O BANCO. IMÓVEL DOADO OFERECIDO EM GARANTIA PELOS DOADORES. INVIABILIDADE DA CONSTRIÇÃO JUDICIAL. EMBARGOS DE TERCEIRO. CABIMENTO E PROCEDÊNCIA. PRECEDENTES. AGRAVO DESPROVIDO. (AgRg. nos EDcl no REsp. 469.709/PB, Rel. Ministro Raul Araújo, Quarta Turma, julgado em 03/12/2013, DJe 03/02/2014). No mesmo sentido de não invalidar a doação por falta do registro: REsp. 476.566/PR, Rel. Ministro Carlos Alberto Menezes Direito, Terceira Turma, julgado em 25/11/2003, DJ 1/03/2004, p. 180). Disponíveis em: <http://www.stj.jus.br>. Acesso em: 1 mar. 2014.

${ }_{61}$ BITTAR, Carlos Alberto. Contratos civis ... cit., p. 44.

62 MIRANDA, Francisco Cavalcanti Pontes de. Tratado de direito privado ... cit., p. 203 e 229.

63 Id. Ibid., p. 203.

64 Id. Ibid., p. 210. 
Para Simão, existe ainda a doação contemplativa/meritória, por um merecimento do donatário, por um ato de mera liberalidade, externando-se o motivo da doação (ex. para o prêmio Nobel da Paz). ${ }^{65}$

Segundo Daniele de Lucena Zanforlin, existe a espécie da doação mista, que seria aquela em que se teria um contrato de compra e venda cujo valor é irrisório perto do valor real do bem. ${ }^{66}$

Ainda, com relação à questão da doação com encargo implica em algo acessório, condicionando a doação ao seu cumprimento, mas não o tornando oneroso. Exemplifica Paulo Lôbo com uma doação para que se possa realizar um tratamento de saúde. O seu descumprimento pode acarretar a revogação da doação. Pode-se citar outro exemplo de doação aos filhos que o casal vier a ter, envolvendo questões do direito sucessório no que diz respeito à capacidade passiva de recebimento de herança, também. ${ }^{67}$

Ressalta o autor que existe a possibilidade de a doação ter seus efeitos condicionados ao casamento do donatário com o doador, não dependendo de aceitação. Estar-se-ia diante de uma doação sob condição suspensiva. Entende o autor ser inconstitucional caso a promessa seja feita por terceiros para que "A" receba uma doação caso se case com "B", diante da liberdade constitucional para a formação da entidade familiar. ${ }^{68}$

Com relação à maneira de se proceder, elas podem ocorrer como forma de subvenção periódica (devendo se extinguir com a morte do doador, salvo estipulação em contrário, não ultrapassando a vida do donatário - art. 545, CC), doação com cláusula de reversão (em caso de pré-morte do donatário o bem retorna ao doador - art. 547, CC), doação universal (que acarreta nulidade absoluta - art. 548, CC), de ascendente para descendente (art. 544, CC) e a doação inoficiosa - art. 549, CC (que serão tratadas em itens apartados), doação entre cônjuges - art. 544, CC, doação do cônjuge adúltero ao seu cúmplice - art. 550, CC (podendo ser anulada), doação conjuntiva - art. 551, CC (feita a mais de uma pessoa) e a entidade futura - art. 554, CC. ${ }^{69}$

O Código Civil não prevê expressamente a promessa de doação, mas nada impede que esta seja estipulada. É comum sua ocorrência em casos de divórcio entre o casal quando estes prometem doar para os filhos o imóvel existente. Tal instituto se equipara ao contrato preliminar. ${ }^{70}$

65 SIMÃO, José Fernando. Direito civil ... cit., p. 128.

${ }_{66}$ ZANFORLIN, Daniele de Lucena. Da doação. In: CAMPOS, Alyson Rodrigo Correira; CASTRO JÚNIOR, Torquato da Silva. Dos contratos. Recife: Nossa Livraria, 2012. p. 139.

67 LÔBO, Paulo. Direito civil ... cit., p. 292.

68 Id. Ibid., p. 300-301.

69 SIMÃO, José Fernando. Direito civil ... cit., p. 131-140.

70 LÔBO, Paulo. Direito civil ... cit., p. 281-290. 
Ao abordar o tema, Pontes de Miranda afirma a duplicidade do emprego de tal instituto: primeiro por ser a promessa de doação uma promessa de contrato de doação e por ser contrato consensual de doação. ${ }^{71}$ No pré-contrato de doação promete-se o contrato real (transferindo-se desde logo a titularidade) ou o contrato consensual (promete-se tal transferência).

Cumpre destacar, por fim, a possibilidade da revogação da doação - art. 555. A doação pode ser revogada por ingratidão do donatário, ou por inexecução do encargo.

Os casos de revogação estão elencados na lei e são semelhantes aos casos de deserdação e o de indignidade, regidos pelo direito das sucessões. Precisa-se de ação de revogação, que tem natureza constitutiva negativa e de cunho pessoal, conforme ensina Pontes de Miranda. ${ }^{72}$

A ação a ser proposta, afirma Nelson Nery Junior e Rosa Maria de Andrade Nery seria a ação revocatória, a ser processada pelo rito comum. ${ }^{73}$

2. Da doação como adiantamento da legítima e da doação inoficiosa

Segundo o art. 544 do Código Civil quando a doação for feita de ascendentes a descendentes, ou de um cônjuge a outro, importa em adiantamento do que lhes cabe por herança. ${ }^{74}$ Seguindo esse entendimento, julgou o STJ:

CIVIL. DOAÇÃO DEASCENDENTEADESCENDENTE. AUSENCIA DE CONSENTIMENTO DE UM DOS FILHOS. DESNECESSIDADE. VALIDADE DO ATO. ART. 171. NÃO E NULA A DOAÇÃO EFETIVADA PELOS PAIS A FILHOS, COM EXCLUSÃO DE UM, SO E SO PORQUE NÃO CONTOU COM O CONSENTIMENTO DE TODOS OS DESCENDENTES, NÃO SE APLICANDO A DOAÇÃO A REGRA INSERTA NO ART. 1.132 DO CODIGO CIVIL. DO CONTIDO NO ART. 1.171 DO CC DEVE-SE, AO REVES, EXTRAIR-SE O ENTENDIMENTO DE QUE A DOAÇÃO DOS PAIS A FILHOS E VALIDA, INDEPENDENTEMENTE DA CONCORDANCIA DE TODOS ESTES, DEVENDOSE APENAS CONSIDERAR QUE ELA IMPORTA EM ADIANTAMENTO DA LEGITIMA. COMO TAL - E QUANDO MUITO - O MAIS QUE PODE O HERDEIRO NECESSARIO, QUE SE JULGAR PREJUDICADO,

\footnotetext{
71 MIRANDA, Francisco Cavalcanti Pontes de. Tratado de direito privado ... cit., p. 201.

72 MIRANDA, Francisco Cavalcanti Pontes de. Tratado de direito privado ... cit., p. 276.

73 NERY JUNIOR, Nelson; NERY, Rosa Maria de Andrade. Código civil comentado. 5. ed. São Paulo: Revista dos Tribunais, 2007. p. 551.

74 BRASIL. Código Civil. Disponível em: <http://www.planalto.gov.br/ccivil_03/leis/2002/L10406.htm>. Acesso em: 5 abr. 2014.
} 
PRETENDER, E A GARANTIA DA INTANGIBILIDADE

DA SUA QUOTA LEGITIMARIA, QUE EM LINHA DE

PRINCIPIO SO PODE SER EXERCITADA QUANDO

FOR ABERTA A SUCESSÃO, POSTULANDO PELA REDUÇÃO DESSA LIBERALIDADE ATE COMPLEMENTAR A LEGITIMA, SE A DOAÇÃO FOR

ALEM DA METADE DISPONIVEL. HIPOTESE EM QUE A MÃE DOOU DETERMINADO BEM A TODOS OS FILHOS, COM EXCEÇÃO DE UM DELES, QUE PRETENDE A ANULAÇÃO DA DOAÇÃO, AINDA EM VIDAADOADORA, POR FALTADE CONSENTIMENTO DO FILHO NÃO CONTEMPLADO. RECURSO NÃO CONHECIDO. ${ }^{75}$

PROCESSUAL CIVIL. CIVIL. RECURSO ESPECIAL. SUCESSÃO. DOAÇÃO. VALIDADE. DOAÇÃO DE PAIS A FILHOS. INOFICIOSIDADE. EXISTÊNCIA. ARTS.: 134, 1.176, 1.576, 1.721 E 1.722 DO CC-16. 1. Recurso especial, concluso ao Gabinete em 20/07/2010, no qual se discute a validade de doação tida como inoficiosa, efetuada pelo de cujus aos filhos do primeiro casamento. Inventário de O.L.P., aberto em 1999. 2. A existência de sentença homologatória de acordo, em separação judicial, pela qual o antigo casal doa imóvel aos filhos, tem idêntica eficácia da escritura pública. Precedentes. 3. A caracterização de doação inoficiosa é vício que, se não invalida o negócio jurídico originário - doação -, impõe ao donatário-herdeiro, obrigação protraída no tempo: de, à época do óbito do doador, trazer o patrimônio à colação, para igualar as legítimas, caso não seja herdeiro necessário único, no grau em que figura. 4. A busca da invalidade da doação, ante o preterimento dos herdeiros nascidos do segundo relacionamento do de cujus, somente é cabível se, e na medida em que, seja constatado um indevido avanço da munificência sobre a legítima, fato aferido no momento do negócio jurídico. 5. O sobejo patrimonial do de cujus é o objeto da herança, apenas devendo a fração correspondente ao adiantamento da legítima, in casu, já embutido na doação aos dois primeiros descendentes, ser equalizado com o direito à legítima dos herdeiros não contemplados na doação, para assegurar a esses outros, a respectiva quota da legítima, e ainda, às respectivas participações em eventuais sobras patrimoniais. 6 . Recurso não provido. ${ }^{76}$

75 REsp. 124.220/MG, Rel. Ministro Cesar Asfor Rocha, Quarta Turma, julgado em 25/11/1997, DJ 13/04/1998, p. 126. Disponível em: <http://www.stj.jus.br>. Acesso em: 5 abr. 2014.

76 REsp. 1198168/RJ, Rel. Ministra Nancy Andrighi, Terceira Turma, julgado em 6/08/2013, DJe 22/08/2013. Disponível em: <http://www.stj.jus.br>. Acesso em: 5 abr. 2014. 
$\mathrm{O}$ art. 549 do Código Civil menciona ser nula a doação quanto à parte que exceder à de que o doador, no momento da liberalidade, poderia dispor em testamento. ${ }^{77}$

Afirma Pablo Stolze Gagliano que "o que o legislador pretendeu, ao resguardar o direito dessa categoria de herdeiros, foi precisamente dar-lhes certo conforto patrimonial, impedindo que o autor da herança disponha totalmente do seu patrimônio". ${ }^{78}$ O doutrinador é contrário à proteção dessa norma, sendo favorável apenas para resguardar direito de descendentes menores. Assevera que tal norma é uma afronta ao direito constitucional de propriedade. ${ }^{79}$

Aliás, deve-se destacar aqui a influência do direito constitucional permeando as relações jurídicas privadas, esclarecendo a doutrina portuguesa que "esta projeção do direito constitucional no direito civil é um fenômeno contemporâneo que, tendo como pressuposto um certo modelo de sociedade e uma certa ideia de Estado, dá resposta normativa a exigências da nossa época." $" 80$

Vale lembrar a opinião do Professor Álvaro Villaça Azevedo que ele prefere dizer que "existe a inclusão do Direito Civil na Constituição e não um Direito Civil Constitucional tendo em vista a necessidade da regulamentação na via ordinária. ${ }^{81}$

Existe aqui, segundo Pontes de Miranda, uma limitação à liberdade de doar (e não uma proibição como ocorre no caso de doação de todo o patrimônio). ${ }^{82}$

$\mathrm{O}$ art. 912 do Código Civil Francês menciona sobre a parte disponível que pode ser deixada livremente pelo de cujus. ${ }^{83}$

Não é permitida a doação inoficiosa no ordenamento atual. Entende-se por doação inoficiosa "aquela em que o doador, no momento da liberalidade, excede a legítima dos herdeiros.” Afirma que a ‘ineficácia’ não atinge todo o contrato, senão apenas o excedente, fazendo-se a redução. ${ }^{84}$

Manuel Baptista Lopes conceitua doação inoficiosa como "quaisquer liberalidades, entre vivos (doações) ou por morte (instituições de herdeiros ou legados contidos em testamentos ou doações causa mortis), que ofendam a legítima dos herdeiros

\footnotetext{
77 BRASIL. Código Civil. Disponível em: <http://www.planalto.gov.br/ccivil_03/leis/2002/L10406.htm>. Acesso em: 5 abr. 2014.

78 GAGLiAnO, Pablo Stolze. O contrato de doação. 3. ed. São Paulo: Saraiva, 2010. p. 58.

79 Id. Ibid., p. 59.

80 RIBEIRO, Joaquim de Sousa. Direito dos contratos: estudos. Coimbra: Coimbra, 2007. p. 8.

81 AZEVEDO, Álvaro Villaça. O direito civil na Constituição. In: MORAES, Alexandre de (Org.). Os 20 anos da Constituição da República Federativa do Brasil. São Paulo: Atlas, 2009. p. 371-379. p. 371.

82 MIRANDA, Francisco Cavalcanti Pontes de. Tratado de direito privado ... cit., p. 244.

83 Code Civil Français. Disponível em: <http://www.legifrance.gouv.fr/affichCode.do;jsessionid=9FEDF9B 6C51FA1CA5AFEB8DE089F884E.tpdjo01v_2?idSectionTA=LEGISCTA000006150544\&cidTexte=LEG ITEXT000006070721\&dateTexte=20140406>. Acesso em: 6 abr. 2014.

84 GOMES, Orlando. Contratos ... cit., p. 238.
} 
legitimários, por ultrapassarem os limites da quota disponível". ${ }^{85}$ Vale lembrar que no Direito português herdeiros legitimários são os descendentes e os ascendentes ${ }^{86}$ Cumpre destacar que em decisão recente o STJ entendeu que mesmo se o herdeiro tenha cedido seus direitos hereditários, ele ainda possui a legitimidade de requerer a anulação da doação inoficiosa. ${ }^{87}$

Pela leitura do art. 549 do CC, exemplifica Pontes de Miranda que se no momento da doação o doador não tivesse herdeiros necessários, válida é toda a doação. Se já existia herdeiro necessário, no que exceder, a doação será nula. Se diferentes doações foram feitas, em havendo herdeiros necessários, deve-se computar todas para verificar a ocorrência ou não da invasão da legítima, não se levando em conta as doações feitas enquanto o doador não tinha herdeiro necessário. ${ }^{88}$

No mesmo sentido assevera Pablo S. Gagliano de que, a contrário senso, se o ato de liberalidade não atingir o direito de herdeiros necessários, a doação é válida. ${ }^{89}$

Para se aferir a invasão da legítima, leva-se em conta o momento da liberalidade e não o dia que falece o doador, o valor da doação e o valor do que seria disponível. A doação é inoficiosa desde que excede o quanto. ${ }^{90}$ Assim também afirma Gagliano sobre a opção legislativa de se considerar o valor do bem ao tempo da liberalidade. ${ }^{91}$

A nulidade atinge a doação, considerando-a inoficiosa não em seu todo, mas apenas na parte que excede a parte disponível. Pela leitura do art. 549, afirma Flávio Tartuce que o seu conteúdo é o da conservação do contrato, que é anexo ao da função social, procurando preservar, dentro do possível, a autonomia privada manifestada na doação. ${ }^{92}$

85 LOPES, Manuel Baptista. Das doações ... cit., p. 235.

86 Id. Ibid., p. 231.

87 DIREITO CIVIL E PROCESSUAL CIVIL. LEGITIMIDADE PARA PLEITEAR DECLARAÇÃO DE NULIDADE EM DOAÇÃO INOFICIOSA. O herdeiro que cede seus direitos hereditários possui legitimidade para pleitear a declaração de nulidade de doação inoficiosa (arts. 1.176 do CC/1916 e 549 do CC/2002) realizada pelo autor da herança em beneficio de terceiros. Isso porque o fato de o herdeiro ter realizado a cessão de seus direitos hereditários não lhe retira a qualidade de herdeiro, que é personalíssima. De fato, a cessão de direitos hereditários apenas transfere ao cessionário a titularidade da situação jurídica do cedente, de modo a permitir que aquele exija a partilha dos bens que compõem a herança. REsp. 1.361.983SC, Rel. Min. Nancy Andrighi, julgado em 18/3/2014. Disponível em: <http://www.stj.jus.br>. Acesso em: 20 maio 2014.

88 MIRANDA, Francisco Cavalcanti Pontes de. Tratado de direito privado ... cit., p. 250.

89 GAGLIANO, Pablo Stolze. O contrato de doação ... cit., p. 60.

90 MIRANDA, Francisco Cavalcanti Pontes de. Tratado de direito privado ... cit., p. 253 e 254.

91 GAGLIANO, Pablo Stolze. O contrato de doação ... cit., p. 61.

92 TARTUCE, Flávio. Manual de direito civil: volume único. Rio de Janeiro: Forense; São Paulo: Método, 2011. p. 622. 
Em julgado recente (março de 2014) o STJ entendeu pela possibilidade de nulidade do ato de liberalidade de patrimônio que tenha ultrapassado a parte disponível, considerando a doação inoficiosa:

\section{CIVIL E PROCESSO CIVIL. IMÓVEIS DOADOS PELOS ASCENDENTES AOS DESCENDENTES COMUNS. HERDEIRA NECESSÁRIA PRETERIDA. LEGITIMIDADE PARA PLEITEAR A NULIDADE DO ATO DE LIBERALIDADE. DOAÇÃO UNIVERSAL NÃO DEMONSTRADA. PATRIMÔNIO TRANSFERIDO QUE ULTRAPASSA A METADE DISPONÍVEL MAIS A LEGÍTIMA DOS DONATÁRIOS. INOFICIOSIDADE. NULIDADE PARCIAL DO NEGÓCIO JURÍDICO. ARTS. ANALISADOS: $1.171,1.175,1.795, \mathrm{CC} / 16 .{ }^{93}$}

A consequência jurídica da violação da norma e invasão da legítima será a nulidade do excesso. Manuel Baptista Lopes afirma que "não estão sujeitos à colação os bens doados por conta da cota disponível do doador. Essa doação só pode ser reduzida por inoficiosidade se prejudicar a legítima dos herdeiros legitimários do doador" ${ }^{94}$ Assevera que pela dispensa o pai não quer a igualdade entre os filhos, ficando apenas sujeita a ser reduzida por inoficiosidade se invadir a legítima. ${ }^{95}$

Para evitar que um descendente receba mais que outro, o art. 544 afirma que o que este herdeiro recebeu antes, importa em antecipação da legítima. Tal artigo deve ter sua leitura feita em consonância com o art. 2.002, que menciona a obrigatoriedade dos descendentes de trazer os bens adiantados, com a finalidade de se igualar a legítima, trazer tais bens à colação, ou seja, conferir qual foi o valor de tal doação do que receberam em vida. Se não o fizerem, sujeitam-se à penalidade da sonegação.

Ensina Carlos Roberto Gonçalves que "a colação procura manter, dentro do possível, a igualdade entre os herdeiros legitimados. É, portanto, a igualdade das quotas hereditárias legítimas, dentro da regulamentação de cada Estado, a base conceitual do instituto da colação". ${ }^{96}$ É o que explica também o art. 2.003 do Código Civil.

No que tange ao valor do bem a ser colacionado, seguindo entendimento do art. 2.004 do Código Civil, afirma o Professor Jorge Shiguemitsu Fujita que, caso o doador não tenha atribuído um valor certo ou estimado, sua avaliação deve ser feita por quanto valia o bem no momento da liberalidade (e não por ocasião da abertura da

\footnotetext{
93 REsp. 1361983/SC, Rel. Ministra Nancy Andrighi, Terceira Turma, julgado em 18/03/2014, DJe 26/03/2014). Disponível em: <http://www.stj.jus>. Acesso em: 5 abr. 2014.

94 LOPES, Manuel Baptista. Das doações. Coimbra: Almedina, 1970. p. 200.

95 Id. Ibid., p. 205-206.

96 GONÇALVES, Carlos Roberto. Direito civil brasileiro: direito das sucessões. 5. ed. São Paulo: Saraiva, 2011. v. 7, p. 538.
} 
sucessão).${ }^{97}$ É o que dispõe também o art. 2.003 em seu parágrafo único, quando menciona de não existirem mais os bens doados.

Cumpre destacar que, caso o doador mencione que o bem doado esteja saindo de sua parte disponível, não será considerado como adiantamento da legítima, sendo, por consequência, conforme preceitua o art. 2.005 do Código Civil, dispensado de colação. Outrossim, esclarece o artigo que, tal bem não pode exceder o que era disponível ao tempo da doação, ou seja, no ato da liberalidade.

Afirmam Flávio Tartuce e José Fernando Simão que a dispensa pode constar do título de doação, em decorrência da autonomia privada do doador ou do testamento, conforme ensina o art. 2.006 do Código Civil. ${ }^{98}$

Deve-se ter atenção neste ponto porque, muito embora o valor do bem doado para aferir se houve ou não invasão da legítima e o qual seria essa parte disponível, é feita no momento da liberalidade, porém, o cálculo da legítima é feito no momento da abertura da sucessão. Dispõe o art. 1.847. "Calcula-se a legítima sobre o valor dos bens existentes na abertura da sucessão, abatidas as dívidas e as despesas do funeral, adicionando-se, em seguida, o valor dos bens sujeitos a colação". 99

A consequência do excesso da doação da parte disponível, segundo o Professor Fujita é a sua redução. "Desse modo, se for feita doação que ultrapasse a porção disponível do doador, no instante da liberalidade, deverá ser promovida sua redução. $\mathrm{O}$ excesso deverá ser calculado com base no quantum dos bens, à época da doação". ${ }^{100}$

Por esta invasão ser ato nulo que não se convalida com o tempo, sua natureza é de imprescritibilidade. Ou seja, esclarece Pablo S. Gagliano que pela leitura do art. 169 do Código Civil, o ato nulo não convalesce no tempo, porém, os efeitos patrimoniais dessa ação de nulidade, quer seja reivindicando a coisa, quer por perdas e danos e até mesmo a petição de herança, essas possuem prazos. ${ }^{101}$

O mesmo entendimento possui Flávio Tartuce. Assevera o autor que a ação de redução (que visa declarar a nulidade da parte inoficiosa) é imprescritível - art. 169, CC. Entende, ainda, que para tal ação nem se faz necessário aguardar o falecimento do doador para sua propositura. ${ }^{102}$ Tal postura parece um tanto estranha já que ninguém pode demandar herança de pessoa viva, conforme prevê o art. 426, ao mencionar o pacto de

97 FUJITA, Jorge Shiguemitsu. Curso de direito civil: direito das sucessões. 2. ed. atual. de acordo com o novo Código Civil (Lei n. 10.406, de 10 de janeiro de 2002). São Paulo: Juarez de Oliveira, 2003. p. 269.

98 TARTUCE, Flávio; SIMÃO, José Fernando. Direito civil: direito das sucessões. 6. ed. Rio de Janeiro: Forense; São Paulo: Método, 2013. v. 6. p. 476.

99 BRASIL. Código Civil. Disponível em: <http://www.planalto.gov.br/ccivil_03/leis/2002/L10406.htm>. Acesso em: 6 abr. 2014.

100 FUJITA, Jorge Shiguemitsu. Curso de direito civil ... cit., p. 270.

101 GAGLIANO, Pablo Stolze. O contrato de doação ... cit., p. 69.

102 TARTUCE, Flávio. Manual de direito civil ... cit., p. 622. 
corvina. Ressalta o autor que muito embora a declaração da nulidade seja imprescritível, os direitos de natureza condenatória são prescritíveis ${ }^{103}$ conforme já apontado no parágrafo anterior.

Conclusões

Consoante se verificou na exposição do assunto, o tema doação permeia todo o Direito Civil, desde a parte geral à parte especial, demonstrando o cuidado que o legislador possuiu ao tentar se evitar qualquer lesão de direitos que possa advir desse instituto. Ainda, tendo em vista que o homem, em suas relações com o próximo, têm relações de cunho patrimonial, da qual o contrato é uma delas.

A classificação dos contratos é feita de modo amplo, mas cabe aqui destacar a elaborada pelo Prof. Álvaro Villaça Azevedo em serem os contratos típicos e atípicos. É a doação uma modalidade de contrato, prevista no Código Civil brasileiro dentre os arts. 538 a 564, afirmando então sua natureza jurídica.

No que tange à polêmica em ser a doação negócio jurídico bilateral ou unilateral, aqui se optou pela parcela da doutrina que entende ser negócio jurídico bilateral, com contrato unilateral, é um contrato pelo qual alguém transfere a outrem um bem de sua propriedade, gerando-lhe o empobrecimento de sua parte e o enriquecimento do donatário.

Conforme preceitua o Código Civil atual, a doação apenas poderá ser feita de bens presentes, sendo nula quando feita da totalidade de bens. Sua classificação seria: contrato unilateral, consensual, gratuito, feita de modo típico e solene.

Pode-se afirmar que dentre as espécies de doação tem-se: doação pura e simples; modal/onerosa/com encargo; remuneratória; contemplativa/meritória; mista; doação sob condição suspensiva. Já com relação à maneira de se proceder ela pode ser: doação com subvenção periódica; com cláusula de reversão; doação universal; de ascendente para descendente; cônjuge; inoficiosa; de cônjuge adúltero ao seu cúmplice; conjuntiva; entidade futura.

Cumpre destacar que a doação quando feita de ascendente para descendente importa em adiantamento da legítima e, é nula se a doação exceder a parte disponível no momento da liberalidade. Desta forma, considera-se doação inoficiosa a doação que excede a legítima dos herdeiros, porém, tal invalidade atinge apenas o excedente.

Deste modo, os descendentes que tiverem recebido bens em antecipação, devem trazê-los à colação sob pena de sonegados. Tal ato tem a finalidade de se igualar a legítima dos herdeiros. Tanto o valor do bem quanto a análise da parte disponível devem

103 Id. Ibid., p. 622. 
ser feitas no momento da liberalidade, porém, o cálculo da legítima é apurado no momento da abertura da sucessão. Após, se houver excesso da parte disponível é que se deve fazer a redução. Para a declaração da nulidade vigora a imprescritibilidade, porém, com relação aos efeitos patrimoniais, estes são prescritíveis.

Londrina, maio de 2014.

\section{Referências}

ALVIM, Agostinho Neves de Arruda. Da doação. 2. ed. atual. São Paulo: Saraiva, 1972.

ASCOLI, Alfredo. Trattato delle donazioni. 2. ed. riv. Milano: Società Editrice Libraria, 1935.

AZEVEDO, Álvaro Villaça. Comentários ao novo código civil: das várias espécies de contrato, da compra e venda e do compromisso de compra e venda. Arts. 481 a 532. Coord. Sálvio de Figueiredo Teixeira 2. ed. Rio de Janeiro: Forense, 2011. v. 7.

. Considerações sobre a venda de ascendente para descendente, ante as súmulas 152 e 494 do STF. Revista de Direito Civil Imobiliário, Agrário e Empresarial, São Paulo, ano 4, n. 13, p. 161-173, jul./set. 1980.

. O direito civil na Constituição. In: MORAES, Alexandre de (Org.). Os 20 anos da Constituição da República Federativa do Brasil. São Paulo: Atlas, 2009. p. 371-379.

. Teoria geral das obrigações e responsabilidade civil. 12. ed. São Paulo: Atlas, 2011.

. Teoria geral dos contratos típicos e atípicos. 3. ed. São Paulo: Atlas, 2009.

1982.

. Venda de ascendente a descendente. Revista dos Tribunais, ano 71, v. 565, p. 39-48, nov.

AZEVEDO, Marcos de Almeida Villaça. Onerosidade excessiva e desequilibrio contratual supervenientes. 2002. Tese (Doutorado) - Faculdade de Direito, Universidade de São Paulo, São Paulo, 2002.

BECK, Ulrich. Sociedade de risco: rumo a uma outra modernidade. Tradução de Sebastião Nascimento. São Paulo: Ed. 34, 2010.

BITTAR, Carlos Alberto. Contratos civis. 3. ed. Rio de Janeiro: Forense Universitária, 2006.

CASULLI, Vincenzo Rodolfo. Donazioni indirette e rinunzie ad eredita o legati. Roma: Foro Italiano, 1950.

ESPÍNOLA, Eduardo. Dos contratos nominados no direito civil brasileiro. Atualizado por Ricardo Rodrigues Gama. Campinas: Bookseller, 2002.

FUJITA, Jorge Shiguemitsu. Curso de direito civil: direito das sucessões. 2. ed. atual. de acordo com o novo Código Civil (Lei n. 10.406, de 10 de janeiro de 2002). São Paulo: Juarez de Oliveira, 2003. 
GAGLIANO, Pablo Stolze. O contrato de doação. 3. ed. São Paulo: Saraiva, 2010.

GALES NAVARRO, Santiago. Todo lo que usted necesita saber sobre herencias, testamentos y donaciones. Barcelona: Inforbook's, [1998?.]

GALGANO, Francesco. Diritto privato. 15. ed., con 7 tavole di diritto comparato. Padova: CEDAM, 2010.

GOMES, Orlando. Contratos. 9. ed. Rio de Janeiro: Forense, 1983.

GONÇALVES, Carlos Roberto. Direito civil brasileiro: direito das sucessões. 5. ed. São Paulo: Saraiva, 2011.

HORBACH, Carlos Bastide. Doação com encargo e revogação. Folha de S.Paulo, São Paulo, 4 abr. 2014. Opinião, Caderno, p. A3. Disponível em: <http://www1.folha.uol.com.br/ opiniao/2014/04/1435530-carlos-bastide-horbach-doacao-com-encargo-e-revogacao.shtml $>$. Acesso em: 4 abr. 2014.

JORGE JÚNIOR, Alberto Gosson. Direito dos contratos. São Paulo: Saraiva, 2013.

LÔBO, Paulo. Direito civil: contratos. São Paulo: Saraiva, 2011.

LOPES, Manuel Baptista. Das doações. Coimbra: Almedina, 1970.

MARQUES, Cláudia Lima. A chamada nova crise do contrato e o modelo de direito privado brasileiro: crise de confiança ou crescimento do contrato? In: MARQUES, Cláudia Lima. (Org.). A nova crise do contrato: estudos sobre a nova teoria contratual. São Paulo: Revista dos Tribunais, 2007. p. 17-86.

MATIELLO, Fabrício Zamprogna. Código civil comentado: Lei n. 10.406, de 10.1.2001. 5. ed. São Paulo: LTr, 2013.

MIRANDA, Francisco Cavalcanti Pontes de. Tratado de direito privado. Parte especial. 2. ed. Rio de Janeiro: Editor Borsoi, 1964. t. 46.

NERY JUNIOR, Nelson; NERY, Rosa Maria de Andrade. Código civil comentado. 5. ed. São Paulo: Revista dos Tribunais, 2007.

RIBEIRO, Joaquim de Sousa. Direito dos contratos: estudos. Coimbra: Coimbra, 2007.

SANSEVERINO, Paulo de Tarso Vieira. Contratos nominados II: contrato estimatório, doação, locação de coisas, empréstimo (comodato-mútuo). São Paulo: Revista dos Tribunais, 2005.

SIMÃO, José Fernando. A boa-fé objetiva: nova disciplina de um velho instituto. Revista da Faculdade de Direito, Fundação Álvares Penteado, São Paulo, ano 3, v. 3, p. 162-178, 2005-2006. . Direito civil: contratos. 2. ed. São Paulo: Atlas, 2007. v. 5. 
SIMÃO, José Fernando. Natureza jurídica do dízimo e da doação: aparente semelhança, mas grandes e insuperáveis diferenças. Disponível em: <http://www.professorsimao.com.br/artigos_ simao_cf0813.html>. Acesso em: 16 mar. 2014.

TARTUCE, Flávio. Manual de direito civil: volume único. Rio de Janeiro: Forense; São Paulo: Método, 2011.

; SIMÃO, José Fernando. Direito civil: direito das sucessões. 6. ed. Rio de Janeiro: Forense; São Paulo: Método, 2013. v. 6.

TOMASEVICIUS FILHO, Eduardo. Uma década da aplicação da função social do contrato: análise da doutrina e da jurisprudência brasileiras. Revista dos Tribunais, v. 103, n. 940, p. 49-85, fev. 2014.

TRABUCCHI, Alberto. Istituzioni di diritto civile. 44. ed. Padova: CEDAM, 2009.

ZANFORLIN, Daniele de Lucena. Da doação. In: CAMPOS, Alyson Rodrigo Correira; CASTRO JÚNIOR, Torquato da Silva. Dos contratos. Recife: Nossa Livraria, 2012.

Sites:

BRASIL. Lei n. 10.406, de 10 de janeiro de 2002. Institui o Código Civil. Palácio do Planalto [da] Presidência da República, Brasília, DF, 2002. Disponível em: http://www.planalto.gov.br/ccivil_03/ leis/2002/L10406.htm. Acesso em: 5 abr. 2014.

MARQUES, Jairo. Brasileiro doa mais para mendigos e igrejas, diz estudo. Folha de S.Paulo, São Paulo, 9 mar. 2014. Cotidiano. Disponível em: <http://www1.folha.uol.com.br/fsp/ cotidiano/155599-brasileiro-doa-mais-para-mendigos-e-igrejas-diz-estudo.shtml.

PORTUGAL. Art. 940. Decreto-Lei n. 47.344, de 25 de novembro de 1966. Código Civil Português. República portuguesa, 1966. Disponível em: <http:/www.igf.min-financas.pt/leggeraldocs/ DL_47344_66_COD_CIVIL_4.htm\#CODIGO_CIVIL_ARTIGO_940>.

http://civil.udg.es/normacivil/estatal/CC/3T2.htm

http://ibdfam.org.br/jurisprudencia/2352/A\%C3\%A7\%C3\%A3o\%20de\%20nulidade \%20 de $\% 20$ ato $\% 20$ jur\%C3\%ADdico.\%20Compra\%20e\%20venda $\% 20$ de $\% 20 \mathrm{im} \%$ C3\%B3vel.\%20 Simula $\%$ C3\%A7\%C3\%A3o.\%20Doa\%C3\%A7\%C3\%A30\%20inoficiosa. Acesso em: 20 mar. 2014.

http://www.jus.unitn.it/cardozo/obiter_dictum/codciv/Lib2.htm

http://www.legifrance.gouv.fr

www.stj.jus.br 
